\section{Mental capacity in psychiatric patients}

\author{
Systematic review \\ DAVID OKAI, GARETH OWEN, HUGH MCGUIRE, SWARAN SINGH, \\ RACHEL CHURCHILL and MATTHEW HOTOPF
}

\begin{abstract}
Background Mental capacity is central to legal and ethical debates on the use of compulsion in psychiatry.
\end{abstract}

\begin{abstract}
Aims To describe the clinical epidemiology of mental incapacity in patients with psychiatric disorders, including interrater reliability of assessments, frequency in the psychiatric population and associations of mental incapacity.
\end{abstract}

\section{Method Cross-sectional studies of capacity to consent to treatment for psychiatric patients were systematically reviewed from Medline, EMBASE and Psyclnfo databases. Information on the reliability of assessments, frequency and associations of mental incapacity was extracted.}

\section{Results Out of 37 papers reviewed,} 29 different capacity assessment tools were identified. Studies were highly heterogeneous in their measurement and definitions of capacity. Interrater reliabilities between tools were high. Studies indicate incapacity is common (median 29\%) but the majority of psychiatric in-patients are capable of making treatment decisions. Psychosis, severity of symptoms, involuntary admission and treatment refusal were the strongest risk factors for incapacity.

Conclusions Mental capacity can be reliably assessed. The majority of psychiatric in-patients have capacity, and socio-demographic variables do not have a major impact but clinical ones do.

Declaration of interest None.
Mental capacity is a multidimensional construct that is a central determinant of an individual's ability to make autonomous decisions. Its assessment has become increasingly important with the move away from the paternalistic role of healthcare professionals towards a greater emphasis on an individual's own treatment decisions (Schneider, 1998). The American Psychiatric Association has developed a model statute which uses a mental capacity test (Stromberg \& Stone, 1983). In many other jurisdictions mental capacity and mental health legislation have developed along different lines to deal with the specific needs of different groups of patients. In both England and Scotland, mental capacity legislation has developed with the aim of providing a framework for people with either severe communication difficulties or cognitive problems (intellectual disability, dementia and other organic brain syndromes). In contrast, mental health legislation has developed with the needs of patients with psychiatric disorders - in particular, although not exclusively, psychotic disorders - in mind. Mental health legislation that does not use capacity tests generally applies a 'status' approach, whereby a wide range of treatments can be given to the patient on the basis of certain general conditions being met (e.g. the presence of a mental disorder, or the presence of perceived risk to the patient or others).

The use of status approaches has numerous implications. Under mental capacity legislation treatments are only provided in the patient's best interests (with particular attention paid to previously expressed wishes, including advance directives, which have legal weight), whereas under mental health legislation best interests do not have to be considered, although in practice many psychiatrists effectively apply a best interests test (Peay, 2003). Further, the use of a 'status' approach means that the patient can be given a range of treatments, even if he or she might have capacity to refuse one or more of these. This has led some to suggest that current status-based approaches are anachronistic and unethical (Szmukler \& Holloway, 1998) and that mental capacity and mental health legislation could be fused (Dawson \& Szmukler, 2006).

A review of emergent case law literature in the USA (Grisso et al, 1997) has resulted in a 'four abilities' model, namely the ability to express a choice about treatment; the ability to understand information relevant to the treatment decision; the ability to appreciate the significance of that treatment information for one's own situation; and the ability to reason with relevant information so as to engage in a logical process of weighing treatment options. Despite the influential work of the MacArthur Foundation (Grisso \& Appelbaum, 1995a,b; Grisso et al, 1995), concern exists regarding the reliability of capacity assessments in individuals with a mental disorder, and the extent to which legislation that uses a capacity test covers the same or different groups of patients as mental health legislation which uses a status approach. Some have pointed to particular areas of perceived difficulty such as the area to appreciation, which may be difficult to operationalise (Saks et al, 2002; Breden \& Vollmann, 2004).

Our aim was to make a systematic review of empirical, quantitative studies of mental capacity in order to answer the following three questions:

(a) Can the mental capacity of a patient be reliably assessed by two or more raters?

(b) What is the proportion of patients with psychiatric disorders in in-patient settings who are judged to lack capacity?

(c) What factors are associated with lack of capacity in individuals with psychiatric disorders?

\section{METHOD}

We aimed to identify all studies relevant to the aims of this review. Inclusion criteria were that the papers should be in the English language, describe defined populations of patients with psychiatric disorders; report quantitative research (i.e. research that produces numerical summaries of results, as opposed to qualitative research), and describe how the assessment of mental capacity was performed; capacity had to be 
assessed in relation to a current treatment decision, as opposed to capacity to make advance directives, capacity to participate in research, testamentary capacity or capacity to stand trial. Studies were excluded if they were conducted on children or young people less than 18 years old; exclusively concerned organic psychiatric disorders (dementia or delirium) or intellectual disability; were case reports, commentaries or review articles; or were retrospective case-note reviews.

\section{Search strategy}

Relevant research articles were identified from a systematic search of electronic databases. These comprised PsycInfo (1967 to July 2006), Medline (1996 to July 2006) and EMBASE (1980 to July 2006). The electronic database search terms were divided into three sets: mental health legislation terms (e.g. Mental Health Act, coercion, patients' rights), disorder terms (e.g. schizophrenia) and capacity terms (e.g. incompetence, capacity, autonomy). The titles and abstracts of all articles generated were examined on the above inclusion and exclusion criteria. If the reviewer was uncertain as to whether an article fulfilled these criteria, the full paper was requested. The main reviewer was D.O. and his decision to include or exclude studies was reviewed for 100 abstracts by G.O. There were disagreements in 10 papers but further examination indicated none would have been eligible for the final review. The interrater reliability of reviewers was good $(\kappa=0.72)$. These searches were augmented by personal correspondence with experts on mental capacity research. Experts were identified from the investigators' prior knowledge and a delegate list from a recent UK seminar which had advertised for researchers working on this area and included several international speakers. The International Journal of Law and Psychiatry was hand-searched from the first to the most recent issue. Finally, the bibliographies of retrieved articles were used to identify further articles.

\section{Data analysis}

Articles were categorised and data extracted corresponding to our three main questions. We extracted data from the full-length articles using forms to ensure the process was standardised. D.O. performed the data extraction but all studies were checked independently by M.H. As the papers were heterogeneous a formal meta-analysis was not attempted. Where possible we present median values and interquartile ranges. Where the data provided were sufficient to calculate a kappa value, we did so in order to provide a uniform measure of interrater reliability.

\section{RESULTS}

The searches identified 15490 references, which were scanned by abstract and title. On the basis of the abstract or title, 367 papers were retrieved; 316 did not meet the inclusion criteria, leaving 51 identified from the electronic search, many of which were known to us already. The original review was broader than the aims of the present paper (including mental capacity in individuals with medical illness or dementia) and we finally identified 37 papers relevant to this review (see data supplement to the online version of this paper).

\section{Capacity assessments}

The included articles reported many different methods for assessing capacity. Three used vignettes (Grisso \& Appelbaum, 1995b; Grisso et al, 1995; Vellinga et al, 2004), which present the participant with a hypothetical patient facing a treatment dilemma, about which the participant is then asked a series of questions. Fourteen devised assessments of capacity for a specific procedure, for instance capacity to consent to electroconvulsive therapy, having a blood test or admission to a psychiatric ward (Appelbaum et al, 1981, 1998; Roth et al, 1982; Norko et al, 1990; Grisso \& Appelbaum, 1991; Janofsky et al, 1992; Bean et al, 1994, 1996; Poythress et al, 1996; Tomoda et al, 1997; Paul \& Oyebode, 1999; Wong et al, 2000, 2005; Vollmann et al, 2003). Sixteen (Hoffman \& Srinivasan, 1992; Grisso et al, 1997; Melamed et al, 1997; Tomoda et al, 1997; Kitamura et al, 1998; Palmer et al, 2002; Bellhouse et al, 2003a,b; Lapid et al, 2003; Vollmann et al, 2003; Cairns et al, 2005a,b; Howe et al, 2005; Jacob et al, 2005; Koren et al, 2005; Beckett \& Chaplin, 2006) used more flexible assessment methods, designed for use with any treatment decision. Studies generally framed capacity either in binary terms (i.e. present or absent for a specific decision) or as a continuous variable measured on a dimensional scale. A third approach adopted by some (Kitamura et al, 1998;
Paul \& Oyebode, 1999) was to describe the participant's ability to meet increasingly stringent (binary) tests of capacity. Such studies combined aspects of both the multidimensional and binary approaches.

\section{Reliability of capacity assessments}

Seventeen studies reported interrater reliability of competency assessments. These had a median sample size of 56 participants (interquartile range 14-62). These studies could be categorised under three broad themes:

(a) binary decisions (capacity present or absent) using the same assessment tool and two or more raters;

(b) binary decisions comparing a clinician's assessment with an assessment made by a clinical researcher using a mental capacity tool;

(c) score on an individual dimension of capacity measured on an assessment tool.

Where available, we report agreement using Cohen's kappa, which is used as a measure of reliability taking into consideration the level of agreement expected by chance. Kappa takes a value between -1 and 1, and we define kappa scores as follows (Landis \& Koch, 1977): <0, poor; 0-0.2, slight; 0.2-0.4, fair; 0.4-0.6, moderate; $0.6-0.8$, substantial; $0.8-1$, almost perfect.

\section{Reliability of binary assessment of mental capacity using interviews}

Five studies (Table 1) assessed mental capacity using two or more raters administering the same structured or semi-structured interview (Roth et al, 1982; Wong et al, 2000; Bellhouse et al, 2003a,b; Cairns et $a l, 2005 b$ ). Methods mainly involved raters assessing the same videotaped or transcribed interview performed by a single

Table I Interrater reliability of mental capacity assessments using same assessment

\begin{tabular}{ll}
\hline Study & $\kappa$ \\
\hline Bellhouse et al (2003a) & 0.74 \\
Bellhouse et al (2003b) & 0.75 \\
Roth et al (1982) & 0.81 \\
Cairns et al (2005a) & 0.82 \\
Wong et al (2000) & 0.87 \\
\hline
\end{tabular}


interviewer, although one paper described the results of two interviews performed by separate interviewers (Cairns et al, $2005 \mathrm{~b}$ ). Assessments used a variety of methods: one (Roth et al, 1982) used a derivative of a 15-item questionnaire (Roth et al, 1977); one used the MacArthur Competence Assessment Tool for Treatment (MacCAT-T) (Cairns et al, 2005b) and one used a semi-structured interview adapted from the MacCAT-T (Wong et $a l, 2000)$. Two papers described interrater reliability on two different decisions (admission and treatment) in similar samples (Bellhouse et al, 2003a,b), using a checklist derived from English legal definitions. Kappa values ranged from 'moderate' to 'almost perfect' (median $\kappa=0.81$ IQR $0.75-0.82$ ). These results suggest that when a consistent approach is taken to the assessment of mental capacity, two or more raters can make a binary assessment with a high level of agreement.

\section{Binary decisions comparing a clinician's assessment and that made by a clinical researcher using a mental capacity tool}

Six studies (Bean et al, 1996; Tomoda et al, 1997; Vollmann et al, 2003; Vellinga et al, 2004; Cairns et al, 2005b; Beckett \& Chaplin, 2006) assessed agreement between an interviewer performing a structured or semi-structured mental capacity assessment and a clinician's view of the patient's mental capacity. The kappa values ranged from 'slight' to 'substantial', (median $\kappa=0.45$, IQR 0.39-0.66). This suggests that when formal assessments are compared with clinical impressions, agreement is well above chance, but not as high as when two raters are using the same assessment tool. Clinicians universally reported fewer patients lacking mental capacity than did researchers.

\section{Other studies comparing agreement using dimensional scales}

Eleven studies addressed interrater agreement on dimensional scales (Norko et al, 1990; Grisso \& Appelbaum, 1991; Janofsky et al, 1992; Bean et al, 1994; Grisso et al, 1995, 1997; Palmer et al, 2002; Vollmann et al, 2003; Cairns et al, 2005b; Wong et al, 2005; Appelbaum \& Redlich, 2006). These studies are difficult to summarise, since they tend to present correlation coefficients between raters on dimensional scales, or give kappa values for sub-scales of multidimensional scales.
Deserving particular mention are the studies of Grisso and Appelbaum on the development of the MacCAT-T and related measures (Grisso et al, 1995, 1997), which present detailed analyses of interrater agreement for each of the dimensions of the MacCAT-T and show that high interrater correlations are the rule. Reliability indices were generally similar for each sub-scale of the MacCAT-T, suggesting that there is no single particularly hard-tomeasure dimension (Grisso et al, 1997; Palmer et al, 2002; Vollmann et al, 2003; Cairns et al, 2005b).

\section{Frequency of mental incapacity in psychiatric patients}

\section{Admission to psychiatric units}

We identified five studies that assessed mental capacity in relation to admission to a psychiatric unit (Appelbaum et al, 1981, 1998; Norko et al, 1990; Poythress et al, 1996; Bellhouse et al, 2003a). One British study (Bellhouse et al, 2003a), described a mixed clinical population of patients and found that $67 \%$ had mental capacity to make the decision. Three studies (Appelbaum et al, 1981, 1998; Norko et al, 1990) described capacity to make this decision among voluntary patients admitted to psychiatric hospital. It is difficult to summarise the results of these studies since each presents more than one measure of incapacity; however, approximately 30 $50 \%$ of participants scored in a range that suggests they were competent to make decisions, a sizeable minority scored in an intermediate range, and as many as $50 \%$ (Norko et al, 1990) had significant impairments of mental capacity despite accepting voluntary admission. One study (Poythress et al, 1996) described patients who were brought to hospital on a court order (of whom half subsequently accepted informal admission), and found that $55 \%$ had an impairment of capacity on a stringent definition and $35 \%$ had impairment on a less stringent definition.

\section{Psychiatric in-patients: other treatments}

Of the remaining studies of psychiatric patients, most described treatment for diverse interventions (Grisso \& Appelbaum, 1991; Hoffman \& Srinivasan, 1992; Janofsky et al, 1992; Grisso et al, 1995, 1997; Billick et al, 1996; Melamed et al, 1997; Tomoda et al, 1997; Kitamura et al, 1998; Melamed et al, 1999; Bellhouse et al, 2003b; Vollmann et al, 2003; Vellinga et al, 2004; Cairns et al, 2005b; Jacob et al, 2005; Beckett \& Chaplin, 2006), whereas a few focused on either antipsychotic medication (Paul \& Oyebode, 1999; Wong et al, 2005) or electroconvulsive therapy (Roth et al, 1982; Bean et al, 1996). In some studies the population was well defined, and a true cross-sectional study of consecutive patients had been performed. In others the population under study was much less well characterised, and convenience samples were used. For those 12 studies that provided a binary (present/ absent) rating of mental capacity in the various psychiatric in-patient groups, estimates ranged from $10 \%$ to $95 \%$ of the participants lacking capacity (Table 2). However, all but two studies estimated that less than half of psychiatric in-patients lacked capacity, and the median value was 29\% (IQR 22-44).

\section{Specific psychiatric diagnoses}

Four studies (Grisso \& Appelbaum, 1995c; Grisso et al, 1997; Vollmann et al, 2003; Appelbaum \& Redlich, 2006) presented the results of capacity assessments for patients with psychiatric diagnoses separately. Three used the MacCAT-T, and compared participants with schizophrenia or depression, all finding that impairments in mental capacity were much more common in the schizophrenia group. The MacArthur study (Grisso et al, 1997) found that $52 \%$ of patients with schizophrenia had impaired capacity, as opposed to $24 \%$ of those with depression. This study gave a further detailed breakdown of areas of difficulty, indicating that when individuals with schizophrenia had difficulties in decisionmaking, their appreciation, understanding and reasoning could all be affected. In contrast, decision-making difficulties in depression were mainly related to difficulties in appreciation. The third study (Vollmann et al, 2003) reported a remarkably consistent result: $53 \%$ of in-patients with schizophrenia were judged to lack capacity, as opposed to $20 \%$ of those with depression.

\section{Associations of mental incapacity in psychiatric patients}

Twenty-seven studies described associations of mental incapacity in psychiatric in-patients. These papers presented a range of variables, including socio-demographic factors (such as age, gender, educational level and ethnicity) as well as patient 
Table 2 Frequency of mental capacity among psychiatric in-patients

\begin{tabular}{|c|c|c|c|}
\hline Study & $\begin{array}{l}\text { Participants } \\
\text { (n) }\end{array}$ & $\begin{array}{l}\text { Participants } \\
\text { rated as having } \\
\text { mental capacity } \\
\%(95 \% \mathrm{Cl})\end{array}$ & Notes \\
\hline Bean et al $(1994,1996)$ & 96 & $78(70-86)$ & $\begin{array}{l}\text { In-patients referred for ECT } \\
\text { (13\% detained) }\end{array}$ \\
\hline Beckett \& Chaplin (2006) & 50 & $38(25-5 I)$ & $\begin{array}{l}\text { In-patients with acute mania only; } \\
\text { clinical assessment }\end{array}$ \\
\hline Bellhouse et al (2003b) & 43 & $80(73-87)$ & $20 \%$ detained \\
\hline Billick et al (1996) & 20 & $75(56-94)$ & \\
\hline Cairns et al (2005b) & 112 & $56(47-65)$ & $\begin{array}{l}\text { Consecutive sample } \\
\text { ( } 32 \% \text { detained) }\end{array}$ \\
\hline Hoffman \& Srinivasan (1992) & 60 & $35(23-47)$ & $47 \%$ of patients detained \\
\hline Janofsky et al (1992) & 41 & $66(5 I-8 I)$ & $\begin{array}{l}\text { Included patients }(n=16) \text { admitted } \\
\text { to general medical ward }\end{array}$ \\
\hline Kitamura et al (1998) & 48 & $76(64-88)$ & Included $48 \%$ medical patients \\
\hline Melamed et al (1997, 1999) & 113 & $66(57-75)$ & All voluntary psychiatric patients \\
\hline Paul \& Oyebode (1999) & 40 & $5(0-13)$ & $\begin{array}{l}\text { All voluntary patients; high stand- } \\
\text { ard of capacity based on presence } \\
\text { of insight into disorder }\end{array}$ \\
\hline Roth et al (1982) & 57 & $71(60-82)$ & $\begin{array}{l}\text { In-patients referred for ECT; } \\
7 \% \text { detained }\end{array}$ \\
\hline Vollman et al (2003) & 109 & $78(70-86)$ & Only voluntary patients \\
\hline Wong et al (2000) & 62 & $90(82-98)$ & II\% detained \\
\hline
\end{tabular}

ECT, electroconvulsive therapy.

variables (such as cognitive abilities and whether the person was accepting or refusing treatment).

\section{Socio-demographic variables}

Fourteen studies (Appelbaum et al, 1981, 1998; Norko et al, 1990; Hoffman \& Srinivasan, 1992; Bean et al, 1996; Billick et al, 1996; Grisso et al, 1997; Melamed et al, 1997; Paul \& Oyebode, 1999; Palmer et al, 2004; Cairns et al, 2005a; Jacob et al, 2005; Wong et al, 2005; Beckett \& Chaplin, 2006) presented results on gender, and none of these indicated an association. Thirteen studies presented results on age, with ten (Appelbaum et al, 1981; Billick et al, 1996; Grisso et al, 1997; Melamed et al, 1997; Palmer et al, 2004; Appelbaum \& Redlich, 2006; Beckett \& Chaplin, 2006; Cairns et al, 2005a; Jacob et al, 2005; Wong et al, 2005) describing no association and three (Roth et al, 1982; Norko et al, 1990; Appelbaum et al, 1998) describing an association with increasing age and mental incapacity. Results on socio-economic status were scarce, but of the four studies presenting associations, two described an association between mental incapacity and lower socio-economic status (Grisso \& Appelbaum, 1995b; Roth et al, 1982), and two described no such association (Billick et al, 1996; Grisso et $a l, 1997)$. For educational attainment, two studies showed an association between incapacity and lower educational status (Roth et al, 1982; Wong et al, 2005) whereas the remaining eight showed no association (Grisso \& Appelbaum, 1991; Billick et al, 1996; Kitamura et al, 1998; Paul \& Oyebode, 1999; Palmer et al, 2004; Cairns et al, 2005a; Appelbaum \& Redlich, 2006; Beckett \& Chaplin, 2006). Seven studies assessed ethnic group, with six finding no association (Norko et al, 1990; Billick et al, 1996; Grisso et al, 1997; Appelbaum et al, 1998; Paul \& Oyebode, 1999; Jacob et al, 2005). The one exception (Cairns et al, 2005a) showed an association between Black and minority ethnic group and mental incapacity, but the Black and minority ethnic group consisted of more individuals with psychotic illness and once this was controlled for the effect of ethnicity was lost.

\section{Clinical variables}

The other main variables to have been examined in the psychiatric studies were broadly clinical. When groups of patients with mixed diagnoses were examined, it was almost universally shown that capacity was more often impaired in individuals with psychotic illness than in individuals with non-psychotic illness (usually depressive disorder) (Grisso \& Appelbaum, 1995c; Bean et al, 1996; Poythress et al, 1996; Bellhouse et al, 2003a; Vollmann et al, 2003; Appelbaum \& Redlich, 2006). Most studies (Grisso \& Appelbaum, 1995b; Billick et al, 1996; Grisso et al, 1997; Cairns et al, 2005a; Howe et al, 2005; Jacob et al, 2005; Wong et al, 2005; Beckett \& Chaplin, 2006) although not all (Paul \& Oyebode, 1999) - showed that severity of psychopathology was also associated with loss of capacity. Perhaps unsurprisingly, individuals who refused treatment were more often considered to be lacking capacity compared with those who accepted it (Roth et al, 1982; Bean et al, 1996; Melamed et al, 1997; Jacob et al, 2005; Wong et al, 2005) and a corresponding feature is that patients admitted involuntarily were more likely to lack capacity (Hoffman \& Srinivasan, 1992; Bean et al, 1996; Poythress et al, 1996; Melamed et al, 1997; Appelbaum et al, 1998; Cairns et al, 2005a). Few studies of psychiatric patients have assessed the cognitive underpinnings of mental incapacity, but one intriguing study (Koren $e t$ al, 2005) showed that although problems with capacity were weakly related to performance on the Wisconsin Card Sorting Test (a measure of executive function), performance on a 'metacognitive' scoring system was much more closely related. The metacognitive scoring system emphasised the level of confidence patients had about their performance, and the degree to which this was at odds with actual performance was predictive of poor performance on the MacCAT-T.

\section{DISCUSSION}

We identified a number of studies that have used a systematic approach to measure mental capacity in individuals with psychiatric disorders. Although the methods used to measure capacity varied considerably, we have been able to address the three aims of this review. Our first aim was to determine whether mental capacity could be 
assessed in a reliable manner. The answer to this question depends upon the study design. Studies that used a standardised assessment reported very high interrater reliabilities, with a median kappa of 0.81 . Despite capacity being a complex, valueladen, multidimensional construct, this finding suggests that it can be assessed with greater reliability than cardiologists interpreting exercise electrocardiograms, radiologists interpreting mammograms or haematologists reading peripheral blood films (Sackett et al, 1991). When interrater reliability of single dimensions of capacity such as understanding is measured, results again suggest that these measures are highly reproducible. It is noteworthy that even dimensions such as reasoning and appreciation, which are hard to operationalise, are assessed with good interrater reliability. However, interviewers using standardised assessments agreed much less frequently with the clinicians who had been treating the study participants, and although this difference may be artefactual (under certain circumstances kappa values may be low despite good agreement) we think that it is probable that reliability is generally lower when a researcher's assessment is pitted against that of a clinician. In general, clinicians were much less likely to judge a patient to lack capacity, and it may be that if a patient is prepared to accept the treatment proposed the issue of incapacity does not arise - the clinician presumes it is present. Clinicians might have a tendency to equate treatment refusal with incapacity and treatment acceptance with capacity. Alternatively, it might be that clinicians lack training or the time in which to perform careful assessments. Finally, although there is no gold standard criterion of capacity, it may be that formal assessments, although reliable, lack specificity and tend to 'overdiagnose' incapacity compared with the clinicians' assessments.

The second question related to the frequency of incapacity to make key treatment decisions among patients with psychiatric disorders. Taking the median values as an approximate estimate, the results of the reviewed studies indicate that of in-patients with psychiatric disorders, a sizeable proportion - usually the majority - are capable of making treatment decisions. Indeed, the frequency of incapacity in psychiatric in-patients found in the reviewed studies did not differ greatly from that in general hospital in-patients (Raymont et al, 2004). The consistency of estimates of incapacity in psychiatric inpatients is striking, given the diverse nature of the populations studied. Half the studies estimated the frequency of participants' lack of capacity to be within the range $22-44 \%$. Similarly, the two studies to report on rates of incapacity in schizophrenia and depression found almost exactly the same rates, despite one being conducted in the USA and the other in Germany, where differences in healthcare systems might have led to differences in patient characteristics. This suggests that although diverse measures of mental capacity have been used, they are capable of making fairly consistent estimates.

The frequency of incapacity in voluntary patients when consenting to admission was remarkably high. This leads to a potential dilemma, as individuals lacking capacity may acquiesce to admission, but may lack protections that an admission under a legal framework would afford. Such patients may, to some extent, feel coerced into accepting admission, presumably since they felt that if they did not agree to an admission they would be detained anyway. Finally, the British studies of mental capacity (Bellhouse et al, 2003a; Cairns et al, $2005 a$ ) in those detained under the Mental Health Act 1983 indicated that a sizeable proportion have capacity to accept or refuse admission to hospital. Further work needs to be done to understand the implications of capacity-based mental health legislation for these individuals.

Mental capacity is not associated with any individual socio-demographic variable apart from advancing age. It is unclear why this should be, but it may be driven by cognitive decline or increased negative symptoms in older patients with psychotic illness. Given that mental capacity assessments are value-laden, it is reassuring that neither gender nor ethnic group has an effect; associations with educational level and social class are inconsistent. The clinical and legal variables associated with mental incapacity in the psychiatric groups should come as no surprise - psychosis, illness severity, involuntary admission and treatment refusal are all consistently reported as risk factors.

\section{Limitations of our review}

The most serious problem of a summary of capacity is that it is by nature a functional definition and to describe the frequency in a specific treatment setting is to ignore the fact that patients may have capacity for some decisions and not for others. It is likely that the variation in the results presented here stems from the heterogeneity of the patient groups, the range of capacity assessment tools used, the different legal standards for capacity assessment and the differences in treatment choices presented to participants. Furthermore, frequency of capacity in some of the primary research was not the main aim of the study and was reported as an incidental finding. Studies were often small, and many were not truly cross-sectional in that they did not define a clear population and sample from it, but instead used convenience samples. Participation rates were frequently unreported, and when they were, were often low. Little information was given about non-participants to allow inferences to be made about non-participation bias.

The primary studies are - with some notable exceptions - particularly weak in their reporting of data on associations. Similar difficulties have been observed in other systematic reviews of descriptive studies (Altman, 2000). We suspect that many of the studies emphasise 'positive' associations and fail to report 'negative' ones. This might lead to a bias, which would mean that conclusions would be more conservative than possibly indicated here. Many studies are statistically underpowered and report negative findings without any consideration of the possibility that a genuine difference was not detected because the sample size was too small. Nevertheless, the generally consistent negative findings in relation to demographic variables probably do reflect a true lack of association.

There are potential limitations of the review methods presented here. This review represents a novel use of systematic review methods, akin to recent developments in summarising information in diagnostics (Straus, 2006). There is a less well-trodden methodology for such reviews compared with reviews of randomised controlled trials. We excluded non-English language papers, and despite considerable effort might have missed relevant eligible papers owing to the diverse language used to describe mental capacity. We did not apply a pre-defined assessment of quality, as we reasoned that the primary studies were too heterogeneous in their designs to do this in a meaningful way. 


\section{Implications}

A number of implications arise from this body of research. First, we have found that most studies report that most psychiatric in-patients are capable of making key treatment decisions; given that as many as a third of general medical patients lack mental capacity (Raymont et al, 2004), this should remind clinicians, policy makers and the general public that patients with psychiatric disorders are not intrinsically different and this may be important in campaigns against stigma. Equally important is the finding that many in-patients with psychiatric disorder lack capacity and there is a tendency for clinicians to underestimate this (especially when patients are accepting treatment) relative to research estimates. This underestimate may have the effect of underestimating clinical and social need. Second, studies are consistent in showing the reliability of mental capacity assessments, and these measurements are correlated with indicators of clinical severity but not with demographic differences. This indicates that mental capacity can be reliably measured, and also that it has some criterion validity. These characteristics mean that it can, we believe, be researched in a useful manner. Third, there is little information on the points where mental capacity and mental health legislation do not overlap. The information from informal admissions suggests that a high proportion of patients may lack capacity - the question then is whether their treatment in an in-patient psychiatric setting is acceptable. A recent ruling by the European Court (HL $v$. United Kingdom, 2005) that the informal hospitalisation of an incompetent patient with intellectual disability was unlawful as he was deprived of his liberty in the absence of required safeguards (the Bournewood case) suggests that mental health providers - in Europe at least - will have to consider much more carefully the legal structures used in healthcare settings which may be judged to deprive individuals of liberty. Much less information exists on patients who have been detained under mental health legislation but are thought to retain capacity; more information is required on the nature of this group, the complexities of capacity assessment within it and the consequences of overriding capable decisions regarding treatment.

\section{ACKNOWLEDGEMENTS}

The study was funded by the Department of Health. The authors are grateful to Professor Genevra
Richardson and Professor George Szmukler for their comments on an earlier draft.

\section{REFERENCES}

Altman, D. G. (2000) Systematic reviews of evaluations of prognostic variables. In Systematic Reviews in Health Care (eds M. Egger, G. Davey Smith \& D. G. Altman), pp. 228-247. BMJ Books.

Appelbaum, P. S. \& Redlich, A. (2006) Impact of decisional capacity on the use of leverage to encourage treatment adherence. Community Mental Health Journal, 42, $121-130$

Appelbaum, P. S., Mirkin, S. A. \& Bateman, A. L. (198I) Empirical assessment of competency to consent to psychiatric hospitalization. American Journal of Psychiatry, 138, II70-1176.

Appelbaum, B. C., Appelbaum, P. S. \& Grisso, T. (1998) Competence to consent to voluntary psychiatric hospitalization: a test of a standard proposed by American Psychiatric Association. Psychiatric Services, 49, 1193-1196.

Bean, G., Nishisato, S., Rector, N. A., et al (1994) The psychometric properties of the Competency Interview Schedule. Canadian Journal of Psychiatry, 39, 368-376.

Bean, G., Nishisato, S., Rector, N. A. et al (1996) The assessment of competence to make a treatment decision: an empirical approach [see comment]. Canadian Journal of Psychiatry, 4I, 85-92.

Beckett, J. \& Chaplin, R. (2006) Capacity to consent to treatment in patients with acute mania. Psychiatric Bulletin, 30, 419-422.

Bellhouse, J., Holland, A. J., Clare, I. C. H., et al (2003a) Capacity-based mental health legislation and its impact on clinical practice: I) admission to hospital. Journal of Mental Health Law, 9-23.

Bellhouse, J., Holland, A. J., Clare, I. C. H., et al (2003b) Capacity-based mental health legislation and its impact on clinical practice: 2) treatment in hospital. Journal of Mental Health Law, 24-36.

Billick, S. B., Naylor, P.W., Majeske, M. F., et al (1996) A clinical study of competency in psychiatric inpatients. Bulletin of the American Academy of Psychiatry and the Law, 24, 505-5II.

Breden, T. M. \& Vollmann, J. (2004) The cognitive based approach of capacity assessment in psychiatry: a philosophical critique of the MacCAT-T. Health Care Analysis, 12, 273-283.

Cairns, R., Maddock, C., Buchanan, A., et al (2005a) Prevalence and predictors of mental incapacity in psychiatric in-patients. British Journal of Psychiatry, 187, 379-385.

Cairns, R., Maddock, C., Buchanan, A., et al (2005b) Reliability of mental capacity assessments in psychiatric in-patients. British Journal of Psychiatry, 187, 372-378.

Dawson, J. \& Szmukler, G. (2006) Fusion of mental health and incapacity legislation. British Journal of Psychiatry, 188, 504-509.

Grisso, T. \& Appelbaum, P. S. (1991) Mentally ill and non-mentally-ill patients' abilities to understand informed consent disclosures for medication: Preliminary data. Law and Human Behavior, 15, 377-388.

Grisso, T. \& Appelbaum, P. S. (1995a) MacArthur Treatment Competence Study: I. Mental illness and competence to consent to treatment. Law and Human Behaviour, 19, 105-126.
Grisso, T. \& Appelbaum, P. S. (1995b) The MacArthur Treatment Competence Study: III. Abilities of patients to consent to psychiatric and medical treatments. Law and Human Behavior, 19, 149-174.

Grisso, T. \& Appelbaum, P. S. (1995c) Comparison of standards for assessing patients' capacities to make treatment decisions. American Journal of Psychiatry, 152 1033-1037.

Grisso, T., Appelbaum, P. S., Mulvey, E. P. et al (1995) The MacArthur Treatment Competence Study: II. Measures of abilities related to competence to consent to treatment. Law and Human Behavior, 19, 127-148.

Grisso, T., Applebaum, P. S. \& Hill-Fotouhi, C. (1997) The MacCAT-T: A clinical tool to assess patients' capacities to make treatment decisions. Psychiatric Services, 48, $|4| 5-14 \mid 9$.

Hoffman, B. F. \& Srinivasan, J. (1992) A study of competence to consent to treatment in a psychiatric hospital. Canadian Journal of Psychiatry, 37, 179-182.

Howe, V., Foister, K., Jenkins, K., et al (2005)

Competence to give informed consent in acute psychosis is associated with symptoms rather than diagnosis. Schizophrenia Research, 77, 21I-214.

Irwin, M., Lovitz, A., Marder, S. R., et al (1985) Psychotic patients' understanding of informed consent. American journal of Psychiatry, 142, I35I-1354.

Jacob, R., Clare, I. C. H., Holland, A. J., et al (2005) Self harm, capacity, and refusal of treatment: implications for emergency medical practice. A prospective observational study. Emergency Medicine Journal, 22, 799-802.

Janofsky, J. S., McCarthy, R. J. \& Folstein, M. F. (1992) The Hopkins Competency Assessment Test: a brief method for evaluating patients' capacity to give informed consent. Hospital and Community Psychiatry, 43, 132-136.

Kitamura, F., Tomoda, A., Tsukada, K., et al (1998) Method for assessment of competency to consent in the mentally ill: rationale, development, and comparison with the medically ill. International Journal of Law and Psychiatry, 2I, 223-244.

Koren, D., Poyurovsky, M., Seidman, L. J., et al (2005) The neuropsychological bias of competence to consent in first-episode schizophrenia: a pilot metacognitive study. Biological Psychiatry, 57, 609-616.

Landis, J. R. \& Koch, G. G. (1977) The measurement of observer agreement for categorical data. Biometrics, $\mathbf{3 3}$, 159-174.

Lapid, M. I., Rummans, T. A., Poole, K. L., et a (2003) Decisional capacity of severely depressed patients requiring electroconvulsive therapy. Journal of $E C T, \mathbf{1 9}, 67-72$.

Melamed, Y., Kimchi, R., Shnit, D., et al (1997) Insight and competence to consent to psychiatric hospitalization. Medicine and Law, 16, 721-727.

Melamed, Y., Kimchi, R., Shnit, D., et al (1999) Clinical assessment of competency to consent to psychiatric hospitalization. International Journal of Law and Psychiatry, 22, 55-64.

Mukherjee, S. \& Shah, A. (200I) The prevalence and correlates of capacity to consent to a geriatric psychiatry admission. Aging and Mental Health, 5, 335-339.

Norko, M. A., Billick, S. B., McCarrick, R. G., et al (1990) A clinical study of competency to consent to voluntary psychiatric hospitalization. American Journal of Forensic Psychiatry, II, 3-15.

Palmer, B. W., Nayak, G. V., Dunn, L. B., et al (2002) Treatment-related decision making capacity in middle- 
aged and older patients with psychosis. American Journal of Geriatric Psychiatry, 10, 207-2II.

Palmer, B. W., Dunn, L. B., Appelbaum, P. S., et al (2004) Correlates of treatment-related decision-making capacity among middle-aged older patients with schizophrenia. Archives of General Psychiatry, 61, 230-236.

Paul, M. \& Oyebode, F. (1999) Competence of voluntary psychiatric patients to give valid consent to neuroleptic medication. Psychiatric Bulletin, 23, 463-466.

Peay, J. (2003) Decisions and Dilemmas. Hart.

Poythress, N. G., Cascardi, M. \& Ritterband, L. (1996) Capacity to consent to voluntary hospitalization: Searching for a satisfactory Zinermon screen. Bulletin of the American Academy of Psychiatry and the Law, 24, 439-452.

Raymont, V., Bingley, W., Buchanan, A., et al (2004) Prevalence of mental incapacity in medical in-patients and associated risk factors: cross-sectional study. Lancet, $364,|42|-1427$

Roth, L., Meisel, A. \& Lidz, C. (1977) Tests of competency to consent to treatment. American Journal of Psychiatry, 134, 279-284.

Roth, L. H., Lidz, C. W., Meisel, A., et al (1982) Competency to decide about treatment or research. International Journal of Law and Psychiatry, 5, 29-50.

Sackett, D. L., Haynes, R. B., Guyatt, G. H. et al (1991) Clinical Epidemiology: A Basic Science for Clinical Medicine (2nd edn). Little, Brown.

Saks, E. R., Dunn, L. B., Marshall, B. J., et al (2002) The California Scale of Appreciation: a new instrument to measure the appreciation component of capacity to consent to research [see comment]. American Journal of Geriatric Psychiatry, 10, 166-174.

DAVID OKAI, BMedSci, MRCPsych, South London and Maudsley NHS Trust, and Academic Department of Psychological Medicine, Institute of Psychiatry, London; GARETH OWEN, BSc, MRCPsych, Academic Department of Psychological Medicine, Institute of Psychiatry, London; HUGH McGUIRE, MSc, Health Service and Public Health Research, Institute of Psychiatry, London; SWARAN SINGH, MD, FRCPsych, DM, Health Sciences Research Institute, University of Warwick; RACHELCHURCHILL, MSc, PhD, Health Service and Public Health Research, Institute of Psychiatry, London; MATTHEW HOTOPF, MSc, PhD, MRCPsych, Academic Department of Psychological Medicine, Institute of Psychiatry, King's College, London, UK

Correspondence: Professor Matthew Hotopf, Department of Psychological Medicine, Institute of Psychiatry, Weston Education Centre, 10 Cutcombe Road, London SE5 9RJ, UK.

Tel: +44 (0) 207848 0778; fax: +44 (0) 207848 5408; email: m. hotopf@iop.kcl.ac.uk

(First received 30 December 2006, final revision 26 February 2007, accepted 5 April 2007)

Schneider, C. (1998) The Practice of Autonomy. Oxford University Press.

Straus, S. (2006) Bridging the gaps in evidence based diagnosis. BMJ, 333, 405-406.

Stromberg, C. \& Stone, A. (1983) Statute: a model state law on civil commitment of the mentally ill. Harvard Journal on Legislation, 20, 275-396.

Szmukler, G. \& Holloway, F. (1998) Mental health legislation is now a harmful anachronism. Psychiatric Bulletin, 22, 662-665.

Tan, J., Hope, T. \& Stewart, A. (2003) Competence to refuse treatment in anorexia nervosa. International Journal of Law and Psychiatry, 26, 697-707.

Tomoda, A., Yasumiya, R., Sumiyama, T., et al (1997) Validity and reliability of structured interview for competency incompetency assessment testing and ranking inventory. Journal of Clinical Psychology, 53. 443-450.
Vellinga, A., Smit, J. H., van Leeuwen, E., et a (2004) Competence to consent to treatment of geriatric patients: judgements of physicians, family members and the vignette method. International journal of Geriatric Psychiatry, 19, 645-654.

Vollmann, J., Bauer, A., Danker-Hopfe, H. et (2003) Competence of mentally ill patients: a comparative empirical study. Psychological Medicine, 33 1463-147|.

Wong, J. G., Clare, I. C. H., Holland, A. J., et al (2000) The capacity of people with a 'mental disability' to make a health care decision. Psychological Medicine, 30, 295-306.

Wong, J. G., Cheung, E. P. T. \& Chen, E.Y. H. (2005)

Decision making capacity of inpatients with schizophrenia in Hong Kong. Journal of Nervous and Mental Disease, 193, 316-322.

HL v. The United Kingdom (2005) 40 EHRR 32. 